\title{
Effects of Combined Tracheal Suctioning and Expiratory Pause: A Crossover Randomized Clinical Trial
}

\author{
Luciane de Fraga Gomes Martins ${ }^{1}$, Wagner da Silva Naue ${ }^{2}$, Amanda Soares Skueresky ${ }^{3}$, Tanara Bianchi $^{4}$,
} Alexandre Simões Dias ${ }^{5}$, Luiz Alberto Forgiarini Junior 6

\begin{abstract}
Aims: Our aim is to compare volume of suctioned secretion, respiratory mechanics, and hemodynamic parameters in intubated patients undergoing closed-system endotracheal suctioning alone (control group) versus closed-system tracheal suctioning with an expiratory pause (intervention group).

Settings and design: Randomized crossover clinical trial.

Materials and methods: Patients who had been on mechanical ventilation for more than 24 hours were randomly assigned to receive closedsystem suctioning alone or closed-system suctioning with an expiratory pause on the ventilator. The following variables were evaluated: heart rate, respiratory rate, mean arterial pressure, peripheral arterial oxygen saturation, peak inspiratory pressure, mechanical ventilator circuit pressure during aspiration, exhaled tidal volume, dynamic compliance, resistance, and weight of suctioned secretion.

Statistical analysis: Compared using the paired $t$-test and general linear model analysis of variance for normally distributed variables (as confirmed by the Kolmogorov-Smirnov test). The Wilcoxon test was used for variables with a nonparametric distribution, while the Chi-square test and Fisher's exact test were used for categorical variables.

Results: The sample comprised 31 patients (mean age, $61.1 \pm 18.2$ years). The amount of secretion suctioned was significantly higher in the intervention group than in the control group ( $1.6 \mathrm{~g}$ vs $0.45 \mathrm{~g} ; p=0.0001)$. There were no significant changes in hemodynamic parameters or respiratory mechanics when comparing pre- and postprocedure time points.

Conclusion: The combination of closed-system endotracheal suctioning and an expiratory pause significantly increased the amount of secretion suctioned compared to conventional suctioning without expiratory pause.

Keywords: Aspirated secretions, Bronchial hygiene, Endotracheal aspiration, Intensive care unit, Respiratory therapy

Key messages: Combination of closed-system endotracheal suctioning and an expiratory pause significantly increased the amount of secretion suctioned.

Indian Journal of Critical Care Medicine (2019): 10.5005/jp-journals-10071-23263
\end{abstract}

\section{INTRODUCTION}

Mechanical ventilation (MV) is an important life-support tool used in the intensive care unit (ICU). ${ }^{1}$ However, critically ill patients often exhibit mucus retention in the airways, and endotracheal intubation is one of the most important risk factors associated with accumulation of such secretions. ${ }^{2}$

Mucus transport also can be influenced by inspiratory and expiratory flows via a two-phase gas-liquid flow mechanism. Thickness of the mucus layer, inspiratory/expiratory air velocity, and mucus viscosity are the critical factors that influence mucus movement through the flow of air. ${ }^{3,4}$

These deleterious effects diminish the effectiveness of mucociliary clearance, causing stasis of secretions in the airways and, thus, bronchial obstruction. ${ }^{3}$ If this obstruction is not reversed, it may result in hypoventilation in the distal airways, atelectasis, and consequent hypoxemia. Accumulation of secretion in the bronchi and unventilated areas facilitate multiplication of microorganisms, which may lead to the development of pneumonia. ${ }^{5-7}$

Mechanically ventilated patients are unable to cough efficiently because of sedation and the presence of the endotracheal tube itself. Two methods are available for endotracheal suctioning, namely, open endotracheal suctioning (OES) and closed endotracheal suctioning (CES). In OES, patients are disconnected from the mechanical ventilator, which leads to more severe hypoxemia and lung volume loss than in CES. However, more airway
1,2,4 Hospital de Clínicas de Porto Alegre, Porto Alegre, Rio Grande do Sul, Brazil

${ }^{3}$ Centro Universitário Metodista - IPA, Porto Alegre, Rio Grande do Sul, Brazil

${ }^{5}$ Hospital de Clínicas de Porto Alegre (HCPA), Universidade Federal do Rio Grande do Sul (UFRGS), Course of Physiotherapy, Postgraduate Program in Pneumology and Human Sciences Movement, Porto Alegre, Rio Grande do Sul, Brazil

${ }^{6}$ Universidade La Salle, Canoas, Rio Grande do Sul, Brazil

Corresponding Author: Forgiarini Junior, Postgraduate Program in Health and Human Development, Universidade La Salle, Canoas, Rio Grande do Sul, Brazil, Phone: 55-51-991365947, e-mail: forgiarini.luiz@ gmail.com

How to cite this article: Martins LFG, Naue WS, Skueresky AS, Bianchi T, Dias AS, Forgiarini Junior LA. Effects of Combined Tracheal Suctioning and Expiratory Pause: A Crossover Randomized Clinical Trial. Indian J Crit Care Med 2019;23(10):454-457.

Source of support: Nil

Conflict of interest: None

secretion is removed in OES than CES, as demonstrated both in animal models and in human patients. ${ }^{8}$ Based on these reasons, both techniques are sometimes used interchangeably. ${ }^{9}$

Two of the major advantages of CES are that it reduces the risk of contamination, thus helps prevent infections, ${ }^{10}$ and avoids

() The Author(s). 2019 Open Access This article is distributed under the terms of the Creative Commons Attribution 4.0 International License (https://creativecommons. org/licenses/by-nc/4.0/), which permits unrestricted use, distribution, and non-commercial reproduction in any medium, provided you give appropriate credit to the original author(s) and the source, provide a link to the Creative Commons license, and indicate if changes were made. The Creative Commons Public Domain Dedication waiver (http://creativecommons.org/publicdomain/zero/1.0/) applies to the data made available in this article, unless otherwise stated. 
depressurization of the system in patients receiving positive endexpiratory pressure (PEEP). ${ }^{11}$ CES has also been used to prevent systemic oxygen desaturation and alveolar collapse. ${ }^{12}$

We hypothesize that the use of an expiratory pause in the mechanical ventilator can increase the effectiveness of CES in relation to the volume of secretion suctioned. Thus, the aim of this study was to compare the efficacy of closed-system aspiration with vs. without an expiratory pause performed directly on the mechanical ventilator and the impact of these two strategies on respiratory mechanics and hemodynamic parameters.

\section{Materials and Methods}

This crossover randomized clinical trial was conducted in the ICU between August 2014 and June 2015. The project was approved by the Research Ethics Committee (protocol no. 14 0444/2014), and written informed consent for all patients was duly provided by their legal guardians or next of kin. Randomization was performed through the online Research Randomizer version 4.0 tool (Social Psychology Network, http://www.randomizer.org/), which was used to select the first suction technique to be used (control or intervention). After 2 hours, patients were crossed over to the other procedure.

Patients were consecutively included if they had been on MV for a period $>24$ hours and $<72$ hours, on a closed-suction system with PEEP $\geq 8 \mathrm{~cm} \mathrm{H} \mathrm{H}_{2} \mathrm{O}$, sedated, under controlled mechanical ventilation, and hemodynamically stable (mean arterial pressure $\geq 60$ and $\leq 120 \mathrm{~cm} \mathrm{H}_{2} \mathrm{O}$ ). The exclusion criteria were clinical diagnosis of pneumothorax, undrained hemothorax, subcutaneous emphysema, influenza $A$ or tuberculosis, peak pressure $>40 \mathrm{~cm}$ $\mathrm{H}_{2} \mathrm{O}$, status postneurosurgery, or refusal to participate.

After inclusion in the study, all patients were positioned supine with the head elevated at an angle of $30^{\circ}$ and received CES three times, performed with a Trach-Care closed-suction system (Pacific Hospital Supply Co. LTD, Taipei, Taiwan), with vacuum set to $-40 \mathrm{~cm} \mathrm{H} \mathrm{H}_{2} \mathrm{O}$ pressure. All patients underwent aspiration 2 hours before performing both study procedures, in order to match the groups in relation to preexisting secretion volume and time of last suctioning procedure.

Patients randomized to the control group were ventilated for 1 minute with $100 \% \mathrm{FiO}_{2}$. Then, vacuum suctioning was performed for 10 seconds, three times. The suctioned secretions were stored in a previously weighed collection bottle (Intermedical ${ }^{\oplus}$; IntermedicalSetmed, São Paulo, Brazil). Hemodynamic and pulmonary parameters were measured before and 1 minute after suctioning.

Patients randomized to the intervention group also underwent aspiration 2 hours before the procedure, following the sequence described above. In these patients, suctioning was performed in a closed system with a 10-second expiratory pause activated directly on the ventilator. As in the control group, the procedure was repeated three times.

The volume of secretion aspirated from each patient was weighed on a Cubis ${ }^{\circledR}$ balance (Sartorius, Bohemia, NY) at the Microbiology Laboratory by a blinded technician who was not part of the study.

The hemodynamic and respiratory parameters of interest were heart rate (HR), respiratory rate (RR), mean arterial pressure (MAP) and peripheral oxygen saturation $\left(\mathrm{SpO}_{2}\right)$. All were collected directly from the ICU monitors (IntelliVue MP60, Philips Medizin Systeme Böblingen $\mathrm{GmbH}$, Böblingen, Germany).
Table 1: Clinical characteristics

\begin{tabular}{ll}
\hline Variable & $n=31$ \\
\hline Age, years & $61,1 \pm 18,2$ \\
APACHE II, score & $22,4 \pm 7,6$ \\
Gender, male & $16(51,6 \%)$ \\
Disease & \\
Sepsis & $8(25,8 \%)$ \\
CPOD & $4(12,9 \%)$ \\
CHF & $4(12,9 \%)$ \\
Pneumonia & $4(12,9 \%)$ \\
Others & $20(64,5 \%)$ \\
\hline
\end{tabular}

Values expressed in mean \pm SD or $n$ (\%). APACHE II, acute physiology and chronic health evaluation; DPOC, doença pulmonar obstrutiva crônica; ICC, insuficiência cardíaca congestiva; COPD, chronic obstructive pulmonary disease; $\mathrm{CHF}$, congestive heart failure

For evaluation of respiratory mechanics, exhaled tidal volume (VTe), resistance (R), and dynamic compliance (Cdyn), were measured at peak inspiratory pressure. These parameters were collected before and 1 minute after the completion of the suctioning techniques. The change $(\Delta)$ in each parameter was calculated as difference between the post- and presuction values.

The sample size needed to obtain a difference of $0.7 \pm 0.9$ grams or more in suctioned secretion volume between the groups, with $p$ $<0.05$ and $80 \%$ statistical power, was calculated as $n=31$.

Data were analyzed using the Statistical Package for the Social Sciences, version 20.0 (SPSS Inc., Chicago, IL, USA). Quantitative data were reported as means and standard deviations, and categorical data, as absolute and relative frequencies. The groups were compared using the paired $t$-test and general linear model analysis of variance for normally distributed variables (as confirmed by the Kolmogorov-Smirnov test). The Wilcoxon test was used for variables with a nonparametric distribution, while the Chi-square test and Fisher's exact test were used for categorical variables. The significance level was set at $5 \%$.

\section{Results}

The study included 31 patients between August 2014 and May 2015. There was a predominance of male patients. The mean age was $61 \pm$ 18.2 years, and the predominant reason for ICU admission was sepsis (25.8\%). The remaining sample characteristics are shown in Table 1.

Within-group comparisons of RR, HR, MAP, VTe, and Cdyn before and after the procedures did not show significant differences. Between-group comparisons of the same parameters also showed no significant differences, as well as the comparison between groups, which was also the behavior observed in the evaluation of the variation of Cdyn. The remaining variables did not differ significantly between groups (Table 2).

Comparison of the amount of secretion suctioned showed a significant increase in the intervention group when compared to the control group ( $p=0.0001)$, as shown in Figure 1. No adverse events such as barotrauma associated with the use of the maneuver were observed.

\section{Discussion}

In the present study, we observed that closed-system endotracheal suctioning combined with an expiratory pause resulted in an increase in the amount of secretion suctioned. In addition, 
Effects of Combined Tracheal Suctioning and Expiratory Pause: A Crossover Randomized Clinical Trial

Table 2: Comparison of hemodynamic and pulmonary parameters in the sample

\begin{tabular}{|c|c|c|c|c|c|c|c|}
\hline & \multicolumn{3}{|c|}{ Control group } & \multicolumn{3}{|c|}{ Intervention group } & \multirow[b]{2}{*}{$p$} \\
\hline & Baseline & Post-treatment & $\Delta$ & Baseline & Post-treatment & $\Delta$ & \\
\hline HR, bpm & $96.1 \pm 18.8$ & $98.9 \pm 17.1$ & $2.8 \pm 8.3$ & $96.7 \pm 19.7$ & $100.3 \pm 18.3$ & $3.6 \pm 11.8$ & 0.709 \\
\hline $\mathrm{RR}$, breaths/min & $20 \pm 5.3$ & $22.6 \pm 6.1$ & $2 \pm 3.7$ & $20 \pm 5.8$ & $21.1 \pm 5.1$ & $1.1 \pm 3.7$ & 0.252 \\
\hline MAP, mm Hg & $77.7 \pm 17.9$ & $82.5 \pm 18.8$ & $4.8 \pm 8.5$ & $80 \pm 18.8$ & $82.2 \pm 19.9$ & $2.1 \pm 6.8$ & 0.164 \\
\hline $\mathrm{PIP}, \mathrm{cm} \mathrm{H}_{2} \mathrm{O}$ & $22.6 \pm 4,3$ & $22 \pm 4.1$ & $-0.5 \pm 2$ & $22.6 \pm 4.3$ & $22 \pm 4.1$ & $-0.5 \pm 2$ & 0.116 \\
\hline Cdyn, $\mathrm{cm} \mathrm{H}_{2} \mathrm{O}$ & $39.7 \pm 13.8$ & $40.8 \pm 15$ & $1.1 \pm 10$ & $41.4 \pm 14.6$ & $40.1 \pm 12.7$ & $-1.2 \pm 6.7$ & 0.159 \\
\hline $\mathrm{VT}, \mathrm{mL}$ & $532.3 \pm 144.1$ & $506.6 \pm 150.1$ & $-25.7 \pm 89$ & $519.6 \pm 125.5$ & $494.8 \pm 149$ & $-24.8 \pm 118.7$ & 0.970 \\
\hline $\mathrm{SpO}_{2}, \%$ & $97.5 \pm 2.6$ & $97.5 \pm 2.6$ & $-0.3 \pm 1.1$ & $97.9 \pm 2.3$ & $96.9 \pm 3.3$ & $-1 \pm 2.6$ & 0.067 \\
\hline $\mathrm{R}$ & $16.9 \pm 6.2$ & $17.2 \pm 5.1$ & $0.1 \pm 4.8$ & $18.9 \pm 5.3$ & $17.6 \pm 6.1$ & $-1 \pm 2.7$ & 0.161 \\
\hline
\end{tabular}

Values expressed in mean $\pm S D$. HR, heart rate; bpm, beats per minute; RR, respiratory rate; bpm, respiratory breaths per minute; MAP, mean arterial pressure; $\mathrm{mm} \mathrm{Hg}$, millimeters of mercury; $\mathrm{SpO}_{2}$, peripheral oxygen saturation; \%, percentage; PIP, peak inspiratory pressure; $\mathrm{cm} \mathrm{H}_{2} \mathrm{O}$, centimeters of water; $\mathrm{VT}$, tidal volume, $\mathrm{mL}$, milliliters; Cdyn, dynamic compliance; $\mathrm{R}$, airway resistance

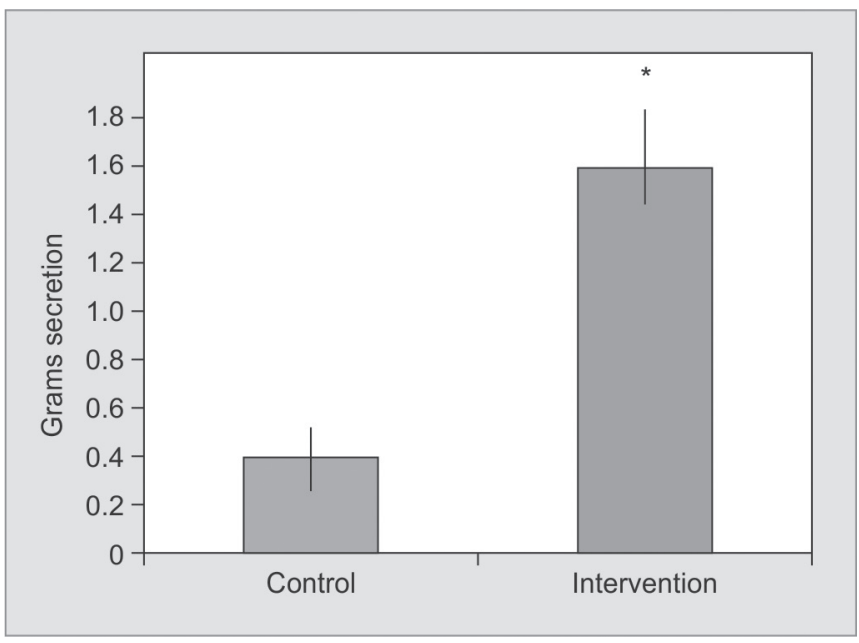

Fig. 1: Comparison of the control group and intervention in relation to the volume of aspirated secretion. ${ }^{*} p=0.0001$

there were no significant changes in respiratory parameters or hemodynamic variables when this tracheal aspiration technique was compared to a conventional technique without expiratory pause.

The use of closed-system suction limits the reduction in lung volume usually associated with tracheal suctioning, confirming that the loss of positive airway pressure caused by disconnection of the ventilator is associated with development of alveolar collapse due to endotracheal suction. This suggests that the use of CES in mechanically ventilated patients with high PEEP levels, who are at higher risk of lung volume reduction secondary air depressurization, can help prevent alveolar collapse and consequent formation of atelectasis. $^{13}$

One of the advantages of CES is its ability to reduce the risk of pulmonary infections due to lack of direct airway exposure and absence of direct handling of the suction probe by a health professional. It has also has been used to reduce the risk of desaturation. ${ }^{12}$ Our findings showed that, regardless of the use or expiratory pause during the procedure, no change in $\mathrm{SpO}_{2}$ was observed.

According to Craig et al., introduction of the suction catheter into the airways without interrupting mechanical ventilation can prevent the fan's ability to provide effective support during aspiration, causing patient-ventilator asynchrony and discomfort. ${ }^{14}$
However, we believe the expiratory pause is a possible alternative to stabilize airway pressure during the procedure, thereby increasing its efficiency while allowing uninterrupted ventilation. It should be noted that all patients included in our study were sedated and in controlled ventilation mode.

We did not detect an increase in Cdyn, which, according to some authors, may be associated with a decreased risk of developing atelectasis. However, it is believed that respiratory therapy techniques can result in improved compliance in mechanically ventilated patients. ${ }^{15,16}$ Naue et al. demonstrated that combined chest compression and increased pressure support significantly increased compliance, tidal volume, and suctioned secretion volume in patients on mechanical ventilation. ${ }^{17}$

Endotracheal suctioning is an invasive procedure. To ensure patient safety, all possible complications should be taken into account and all available preventive procedures should be performed. ${ }^{18}$ While desaturation and bleeding are reportedly very common complications during this procedure, ${ }^{19}$ we did not observe significant changes in $\mathrm{SpO}_{2}$ or any episodes of bleeding in the present study.

Tracheal suction-induced desaturation results from lung derecruitment secondary to both the loss of positive airway pressure caused by ventilator disconnection and the application of negative pressure, particularly in patients with ARDS. ${ }^{20,21}$ The duration of the suctioning procedure, the level of negative pressure applied, the size of the suction catheter, and instillation of saline may also influence the occurrence of derecruitment and hypoxia. Partial prevention of derecruitment can be obtained by avoiding ventilator disconnection or using a closed system. ${ }^{22,23}$

This was the first study to describe the use of an expiratory pause maneuver performed directly on the mechanical ventilator during CES and demonstrate a significant increase in the volume of suctioned secretion. The mechanism underlying this finding is not entirely clear as well as the impact of different expiratory pause times. One possible hypothesis is that the expiratory pause stabilizes air pressure, resulting in greater effectiveness of negative pressure during tracheal aspiration. Further studies should be conducted to identify the physiological mechanisms that enabled this novel result.

We conclude that the combining endotracheal suction with an expiratory pause increases the volume of suctioned secretion without altering hemodynamic parameters or respiratory mechanics. 


\section{References}

1. Almgren B, Wickerts CJ, Heinonen E, Högman M. Side Effects of Endotracheal Suction in Pressure and Volume-Controlled Ventilation. Chest. 2001;125:1077-1080.

2. Bassi GL, Saucedo L, Marti JD, Rigol M, Esperatti M, Luque N, et al. Effects of duty cycle and positive end-expiratory pressure on mucus clearance during mechanical ventilation. Crit Care Medicine. 2012;40:895-902.

3. Benjamin RG, Chapman GA, Kim CS. Removal of bronchial secretions by two-phase gas-liquid transport. Chest. 1989;95:658-663.

4. Kim CS, Rodriguez CR, Eldridge MA. Criteria for mucus transport in the airways by two-phase gas-liquid flow mechanism. J Appl Physiol. 1986;60:901-907.

5. Amato $M B$, Carvalho $C R$, Isola $A$. Mechanical ventilation in Acute Lung Injury (ALI)/Acute Respiratory Discomfort Syndrome (ARDS). J Bras Pneumol. 2007;33(Suppl 2S):S119-S127.

6. Bhowmik A, Chahal K, Austin G. Improving mucociliary clearance in chronic obstructive pulmonary disease. Respir Med. 2009;103:496502 .

7. Ntoumenopoulos G, Presneill JJ, McElholum M. Chest physiotherapy for the prevention of ventilator-associated pneumonia. Intensive Care Med. 2002;28:850-856.

8. Copnell B, Tingay DG, Kiraly NJ, Sourial M, Gordon MJ, Mills JF, et al. A comparison of the effectiveness of open and closed endotracheal suction. Intensive Care Med. 2007;33:1655-1662.

9. Lindgren S, Odenstedt H, Olegard C, Sondergaard S, Lundin S, Stenqvist $\mathrm{O}$. Regional lung derecruitment after endotracheal suction during volume- or pressure-controlled ventilation: a study using electric impedance tomography. Intensive Care Med. 2007;33:172180.

10. Combes $P$, Fauvage B, Oleyer C. Nosocomial pneumonia in mechanically ventilated patients: a prospective randomised evaluation of the Stericath closed suctioning system. Intensive Care Med. 2000;26:878-882.

11. Weitl J, Betterstetter $\mathrm{H}$. Indications for the use of closed endotracheal suction: artificial respiration with high positive end-expiratory pressure. Anaesthesist. 1994;43:359-363.
12. Cereda M, Villa F, Colombo E. Closed system endotracheal suctioning maintains lung volume during volume-controlled mechanical ventilation. Intensive Care Med. 2001;27:648-654.

13. Maggiore SM, Lellouche F, Pigeot J, Taille S, Deye N, Durrmeyer $X$, et al. Prevention of Endotracheal Suctioning-induced Alveolar Derecruitment in Acute Lung Injury. Am J Respir Care Med. 2003;167:1215-1224.

14. Craig KC, Benson MS, Pierson DJ. Prevention of arterial oxygen desaturation during closed-airway endotracheal suction: effect of ventilator mode. Respir Care. 1984;29:1013-1018.

15. Ragnarsdóttir $M$, Kristjánsdóttir Á, Ingvarsdóttir I, Hannesson $P$, Torfason B, Cahalin L. Short-term changes in pulmonary function and respiratory movements after cardiac surgery via median sternotomy. Scand Cardiovasc J. 2004;38(1):46-52.

16. Ciesla ND. Chest physical therapy for patients in the intensive care unit. Phys Ther. 1996;76(6):609-625.

17. Selsby D, Jones JG. Some physiological and clinical aspects of chest physiotherapy. Br J Anaesth. 1990;64(5):621-631.

18. Restrepo RD, Brown JM. 2nd, Hughes JM. Endotracheal Suctioning of Mechanically Ventilated Patients with Artificial Airways 2010. Respir Care. 2010;55:758-764.

19. Maggiore SM, Lellouche F, Pignataro C, Girou E, Maitre B, Richard $J C$, et al. Decreasing the adverse effects of endotracheal suctioning during mechanical ventilation by changing practice. Respir Care. 2013;58(10):1588-1597

20. Lindgren S, Almgren B, Högman M, Lethvall S, Houltz E, Lundin S, et al . Effectiveness and side effects of closed and open suctioning: an experimental evaluation. Intensive Care Med 2004;30(8):1630-1637.

21. American Association for Respiratory Care. Clinical Practice Guidelines. Endotracheal suctioning of mechanically ventilated patients with artificial airways 2010. Respir Care 2010;55(6):758-764.

22. Tingay DG, Copnell B, Grant CA, Dargaville PA, Dunster KR, Schibler A The effect of endotracheal suction on regional tidal ventilation and end-expiratory lung volume. Intensive Care Med 2010;36(5):888-896.

23. Maggiore SM, Volpe C. Endotracheal suctioning in hypoxemic patients. Réanimation 2011;20(1):12-18. 